\title{
ROLE OF REINFORCING AGENTS ON MECHANICAL PROPERTIES OF POM BASED HYBRID COMPOSITES
}

\author{
KRISHNA $^{1}$, B. SURESHA ${ }^{2} \&$ H. M. SOMASHEKAR ${ }^{3}$ \\ ${ }^{1,2}$ Department of Mechanical Engineering, Vidyavardhaka Polytechnic, Mysuru-570002, India \\ ${ }^{2}$ Centre for Composite Materials Research, Department of Mechanical Engineering, The National Institute of Engineering, \\ Mysuru-570008, India \\ ${ }^{3}$ Department of Mechanical Engineering, Dr. Ambedkar Institute of Technology, Bengaluru, India
}

\begin{abstract}
Silicone rubber, PTFE, aramid fiber and molybdenum disulphide reinforcing materials modify the mechanical properties of polyoxymethylene (POM). In the current research work, the roles of these reinforcing materials on the physical and mechanical properties of the POM composites were evaluated. A remarkable synergistic effect between the AF and MoS, in improving the tensile strength and impact strength of POM based composites was demonstrated. The mechanical strength depends on the fiber/filler loading over the full range of the study. The tensile strength of AF/PTFE/SC/POM hybrid composites was $28.6 \%$ higher than that of the POM alone, compared to only a $23.8 \%$ increase in tensile strength for $\mathrm{MoS}_{2} / \mathrm{AF} / \mathrm{PTFE} / \mathrm{SC} / \mathrm{POM}$ hybrid composites over the pristine POM. Also, impact strength increased by $135.8 \%$ using AF/PTFE hybrid fillers and $107.9 \%$ for $\mathrm{MoS}_{2}$ filler in SC-POM blend, compared to unreinforced POM. Scanning electron microscope images of the fracture surfaces of the POM matrix showed that AF/MoS fillers exhibited higher solubility and better compatibility than PTFE/SC-POM composites. The morphological investigation indicates that the fiber pull-out and fiber breakage both donate energy dissipation to the tensile fracture of the composites.
\end{abstract}

KEYWORDS: Reinforcing agents, Polyoxymethylene, Hybrid composites, Mechanical properties, Morphology

Received: Jun 08, 2020; Accepted: Jun 28, 2020; Published: Aug 29, 2020; Paper Id.: IJMPERDJUN2020950

\section{INTRODUCTION}

Polymer matrix composites (PMC's) being a vital class of materials have attracted researchers in recent period in the field of material science for numerous applications ranging from the structural components for houses and buildings, to aerospace and miscellaneous. This is owing to their lower weight, alternatives to metallic materials. Various fillers and reinforcements are added to the pure polymers to improve their properties [1-3]. Solid lubricants are added to help in developing a continuous transfer film between the two counterparts and accordingly reduce the frictional coefficient [4].

Polyoxymethylene (POM), also known as acetyl, polyacetal and polyformaldehyde, is an engineering thermoplastic used in precision parts that require high stiffness, low friction and excellent dimensional stability [5, 6].POM displays a representative helical chain arrangement [7] which is self-possessed alternating carbon-hydrogen bonds. As a consequence, POM shows a high degree of uniformity in its molecular chain, which bestows POM with outstanding solvent confrontation and self-lubricating property [8, 9].POM has excessive crystallinity, strong and stiff material (10-12). Conversely, POM has been widely used as self-lubricating materials in numerous fields of engineering. The POM blends have been much less studied, for instance, Wang [13] studied the thermal stability of 
POM and its blends with polyethylene methyl acrylate (EMA) or poly (styrene-butadiene-styrene) (SBS). The consequences indicated that POM blends with SBS or EMA had similar degradation performance as POM, but addition of SBS enhanced the POM degradation significantly. Multifunctional composite substances (MCM) can be prepared with the help of addition of best performance silicone rubber to gain significant mechanical, thermal and morphological properties and also more cost effective composite materials [14]. Thermoplastic like, polyetherimide (PEI) packed with silicone rubber nanocomposite, properties has attracted unbelievable deal of interest in modern years [15, 16]. PTFE solid lubricant is an engineering plastic, has been mostly used in industrial fields because of superior thermal stability, properly solvent resistance and low friction. polytetrafluoroethylene (PTFE) and molybdenum disulfide $\left(\mathrm{MoS}_{2}\right)$ play as solid lubricants and alter the interface by creating a lubricant film. Here, the composite has lower strength and load-carrying capacity but lower coefficient of friction and wear [17-20].

Simona Matei et al. [21] studied physico-mechanical properties of the composites with short fibers reinforced epoxy matrix. Fibers used in this study were glass and Kevlar fibers. They observed that the glass fiber reinforced composites have much better than Kevlar reinforced composites. Herbert et al [22] examined the mechanical properties such as tensile, compressive, flexural strength and modulus of Kevlar-49 thermoplastic based composites were experimentally obtained and compared with the theoretical estimates. They observed that theoretical values were greater than experimental ones. Prashanth et al. [23] investigated various properties of synthetic fibers such as glass fiber, carbon fiber and Kevlar fiber which also includes the study of the respective fiber reinforced composites. They concluded that the Kevlar is more resistant to fatigue, while carbon and glass are not totally sensitive to fatigue. Kevlar has strong abrasion resistance. Carbon fiber is highly stable and is relatively non-sensitive to chemical degradation.

Sarikanat et al. [24] explored the impact behavior of glass fiber reinforced high-density (HDPE) and low-density polyethylene (LDPE) composite. They established that the fiber directions were significant parameter for the tensile test of composite materials. The polypropylene (PP) composites reinforced with aramid fabric and the effects of impregnation time and compression molding pressure on mechanical properties were studied by Cuong et al. [25].Karger-Kocsis [26] inspected the effects of anisotropy on aramid fabric/PEEK (polyetheretherketone) and aramid fabric/PET (polyethylene terephthalate) strength of composites. Fakhar et al. [27] explored tribological properties of POM composites with short aramid fiber (ASF) and PTFE. Tribological measurements showed that both additives reduced the friction and wear of POM composites. Still, both additives reduced the breaking energy of the POM in the impact test. Then again, the results of the tensile strength showed that the addition of ASF mechanically strengthened the POM while the PTFE declined the mechanical properties of the composition.Polytetrafluoroethylene (PTFE) is liable to slip due to its weak intermolecular interaction. Though, pure PTFE cannot be used as structural material due to its inherently low mechanical strength [28]. As a consequence, PTFE has been embraced as an effective filler to augment the mechanical properties of polymers

In this study, PTFE, short aramid fibers (AFs) and $\mathrm{MoS}_{2}$ reinforcing agents into POM blend (POM+Silicone rubber) as functional reinforcements via melt blending. The influence of these functional reinforcing agents on the physical and mechanical properties and morphology of POM composites was investigated in detail. Characteristic techniques include density test, tensile, flexural, and Izod impact tests, as well as fractography using scanning electron microscopy. 


\section{MATERIALS, FABRICATION AND CHARACTERIZATION}

\section{Materials}

Polyoxymethylene (POM), commercially available in the form of granules is the matrix material, Polytetrafluoroethylene (PTFE) a solid lubricant used as particle of size about $0.015 \mathrm{~mm}$ both were procured from Du Pont Co. Ltd. for the present study. Aramid fiber (AF) was selected as reinforcement and the average diameter of the AFs was approximately $12 \mu \mathrm{m}$ with an average fiber length of about $3 \mathrm{~mm}$ and purchased from Teijin India Pvt. Ltd. Pune. Silicone rubber (SR) used as alloying filler selected to get polymer blend procured from Chezest Enterprise, Chennai. Molybdenum disulphide ( $\left.\mathrm{MoS}_{2}\right)$ was selected as filler purchased from M/s Omkar specialty chemicals Ltd, Thane, with an average particle size of about 5$10 \mu \mathrm{m}$. The characteristic materials used in the present work were summarized in Table 1.

Table 1: Characteristics of Materials used for the Study

\begin{tabular}{|l|c|c|l|}
\hline \multicolumn{1}{|c|}{ Polymer /Filler } & Designation & Density $\left(\mathbf{g} / \mathbf{c m}^{\mathbf{3}}\right)$ & \multicolumn{1}{c|}{ Source and Supplier } \\
\hline Polyoxymethylene & POM & 1.42 & DuPont Co. Ltd. \\
\hline Silicone rubber & SR & 1.30 & Chezest Enterprise, Chennai \\
\hline Polytetrafluroethylene & PTFE & 2.16 & DuPont Co. Ltd. \\
\hline Aramid fiber & AF & 1.39 & Teijin India Pvt. Ltd. Pune \\
\hline Molybdenum disulphide & $\mathrm{MoS}_{2}$ & 4.77 & M/s Omkar specialty chemicals Ltd, Thane \\
\hline
\end{tabular}

\section{Fabrication of POM and Its Composites}

Prior to compounding, the pellets of polymers and the stuffing constituents had been dried at $75^{\circ} \mathrm{C}$ for a period of $10 \mathrm{~h}$ in an oven. The targeted compositions were varied and drawn into elements in Barbender co-rotating dual-screw extruder (Make: CMEI, Model: 16CME, SPL, chamber size $70 \mathrm{~cm}^{3}$ ). The mixing speed of $100 \mathrm{rpm}$ was maintained for all the compositions. The temperatures maintained in three zones of the barrel were $200^{\circ} \mathrm{C}, 235^{\circ} \mathrm{C}$, and $260^{\circ} \mathrm{C}$, respectively. The drawn strands had been chopped into pallets and dried in an airborne kiln at a temperature of $80^{\circ} \mathrm{C}$ for a period of $10 \mathrm{~h}$. The details of the composites fabricated for present investigation are given in Table 2.

Table 2. Constituents of the Polymer Material Composite System for Current Study

\begin{tabular}{|l|c|c|c|c|c|c|}
\hline \multicolumn{1}{|c}{ Composites } & Designation & POM & SR & PTFE & AF & MoS $_{2}$ \\
\hline POM & POM (C) & 100 & - & - & - & - \\
\hline POM+SR & POM1(C1) & 90 & 10 & - & - & - \\
\hline POM+SR+PTFE & POM2(C4) & 85 & 10 & 5 & - & - \\
\hline POM+SR+PTFE+AF & POM3(A1) & 70 & 10 & 5 & 15 & - \\
\hline POM+SR+PTFE+AF +MoS 2 & POM4(A4) & 68 & 10 & 5 & 15 & 2 \\
\hline
\end{tabular}

\section{Characterisations of Composites}

Density of composites was measured according to ASTM standard using METTLER AE 200 densitometer. The specimen is weighed in air, and then weighed after immersion in distilled water at $23^{\circ} \mathrm{C}$ using a sinker and a wire to hold the specimen which was completely submerged. Theoretical density $\left(\rho_{\mathrm{ct}}\right)$ and Void fraction of the composites may be calculated using equation.

$$
\begin{aligned}
\rho_{e t} & =\frac{1}{\left(W_{f} / \rho_{f}\right)+\left(W_{m} / \rho_{m}\right)+\left(W_{p} / p_{p}\right)} \\
V_{v} & =\frac{\rho_{e t}-\rho_{a t}}{\rho_{e t}}
\end{aligned}
$$


Where, $\rho_{\mathrm{ct}}$ and $\rho_{\mathrm{ce}}$ represents theoretical and experimental densities of composites and $\mathrm{W}$ represents weight fraction and the suffix $\mathrm{f}, \mathrm{m}$ and $\mathrm{p}$ are fiber, matrix and particulate fillers respectively and $\mathrm{V}_{\mathrm{v}}$ represents void fraction.

Hardness test of the composite specimens was carried out as per ASTM standard by means of HP-E II series digital Durometer. Durometer has original pressure mechanism, which confirms a continual contact pressure as per standards, eliminating measuring errors caused and influenced by slanting or slope contact. The measured value will be shown on the display.

The tensile and flexural tests were carried out as per ASTM standard using universal testing machine (Kalpak, capacity $1-100 \mathrm{kN}$ ). For a tensile test, effective length of $70 \mathrm{~mm}$ specimen and the cross-head speed of $25 \mathrm{~mm} / \mathrm{min}$ was set and carried out at room temperature. Tensile strength and modulus values were found from the load-displacement curves. In case of flexuraltest, the span length was set at about $60 \mathrm{~mm}$, testing speed was set at $5 \mathrm{~mm} / \mathrm{min}$ and the test was carried out at room temperature. Flexural strength and modulus were estimated from the load and displacement diagrams

Izod impact test was conducted according to ASTM standard with the use of impact testing machine (Make: International equipment's, Mumbai). A notch of $1.84 \mathrm{~mm}$ width with protected prospective of $45^{\circ}$ was generated on the sample.

The micro structures of fractured surfaces of different composites were inspected using scanning electron microscope (JEOL, JSM-5510 SEM, Japan). The entire mechanical tests have been carried out for an average of three samples before analysis being done.

\section{RESULTS AND DISCUSSIONS}

\section{Density and Void Fraction}

Density is a physical property of material which is of major importance in numerous weight sensitive applications. Hence, in various such applications polymer composites are found to substitute conventional metals and materials mainly for their low densities. Density of a composite mainly depends on the relative percentage of matrix and the reinforcing materials. Because of presence of voids and pores, there is a variance exists between the measured and the theoretical density values of composite. Some of the mechanical properties and the performance of composites are affected considerably by these voids. The familiarity of void content is necessary for assessment of the quality of the composites. In the present work, the theoretical and measured densities of POM/SR (POM1) blend filled by particulates with and without aramid fiber composites, along with the equivalent volume fraction of voids are presented in Table 3.

Table 3: Density and Voids of POM and Its Composites

\begin{tabular}{|l|c|c|c|}
\hline \multirow{2}{*}{ Composites } & \multicolumn{3}{|c|}{ Physical Properties } \\
\cline { 2 - 4 } & Theoretical Density $\left(\mathbf{g} / \mathbf{c m}^{3}\right)$ & Measured Density $\left(\mathbf{g} / \mathbf{c m}^{3}\right)$ & Voids(\%) \\
\hline POM (C) & 1.420 & $1.420 \pm 0.02$ & 0.00 \\
\hline POM1(C1) & 1.414 & $1.390 \pm 0.04$ & 1.69 \\
\hline POM2(C4) & 1.433 & $1.440 \pm 0.03$ & 2.02 \\
\hline POM3(A1) & 1.426 & $1.392 \pm 0.02$ & 2.38 \\
\hline POM4(A4) & 1.447 & $1.401 \pm 0.04$ & 3.18 \\
\hline
\end{tabular}

It is also established that the density of composite values calculated theoretically are different from experimentally measured values. It is clear from Table 2 that the density of compositePOM4measures highest and composite POM1 measures lowest in the composite group. Also noted from the table that there is gradual increase in voids of composite with 
higher filler loadings, this may be due to cluster and decrease in voids for lower filler loading might be due to lower volume, and good as well as better interfacial bonding between the POM/SR composites.

\section{Hardness Analysis}

Table 4 summarizes and Figure 1 shows the hardness values of the POM/SR blend based hybrid composites with and without fiber. Hardness values of POM1 and POM2reduced by 7\% and 4\%respectively compared to neat POM. Bijwe et al. [29] reported that inclusion of PTFE into PEEK composite decreases the hardness value.CompositesPOM3andPOM4 in which aramid fiber \& $\mathrm{MoS}_{2}$ were included has improved their hardness values by $11 \%$ and $8 \%$ respectively compared to neat POM. Hemanth et al. [30] investigated that the hardness value of glass fiber reinforced POM composite has improved better than pristine POM compared to POM filled with PTFE composite. It is clearly noticed that the hardness values of composites reinforced by aramid fibers showed superior to that of the composites without fibers. This improvement in hardness value attributed to enhance bonding between matrix, short fiber and fillers.

Table 4.Mechanical Properties of POM/SR Blend Composites

\begin{tabular}{|c|c|c|c|c|c|c|c|c|}
\hline $\begin{array}{c}\text { Composite } \\
\text { (code) }\end{array}$ & $\begin{array}{c}\text { Density } \\
\left(\mathrm{gcm}^{-3}\right) \\
\text { Theoretical }\end{array}$ & $\begin{array}{c}\text { Density } \\
\left(\mathrm{gcm}^{-3}\right) \\
\text { Experimental }\end{array}$ & $\begin{array}{l}\text { Hardness } \\
\text { (Shore-D) }\end{array}$ & $\begin{array}{l}\text { Tensile } \\
\text { strength } \\
\text { (MPa) }\end{array}$ & $\begin{array}{c}\text { Tensile } \\
\text { modulus } \\
(\mathrm{MPa})\end{array}$ & $\begin{array}{c}\text { Flexural } \\
\text { Strength } \\
\text { (MPa) }\end{array}$ & $\begin{array}{c}\text { Flexural } \\
\text { modulus } \\
(\mathrm{MPa})\end{array}$ & $\begin{array}{c}\text { Impact } \\
\text { strength } \\
(\mathrm{J} / \mathrm{m})\end{array}$ \\
\hline POM (C) & & $1.420 \pm 0.02$ & & & & & & 84.55 \\
\hline & & & & & & & & \\
\hline$\overline{\mathrm{POM}}$ & & & & & & 49 & 5.00 & 156.95 \\
\hline POM3(A1) & 1.426 & $1.392 \pm 0.02$ & & 72.56 & 2456.00 & 128.25 & 3350.12 & 199.40 \\
\hline POM4(A4) & 1.447 & $1.401 \pm 0.04$ & 70.30 & 69.85 & 2765.00 & 122.54 & 3125.25 & 175.82 \\
\hline
\end{tabular}

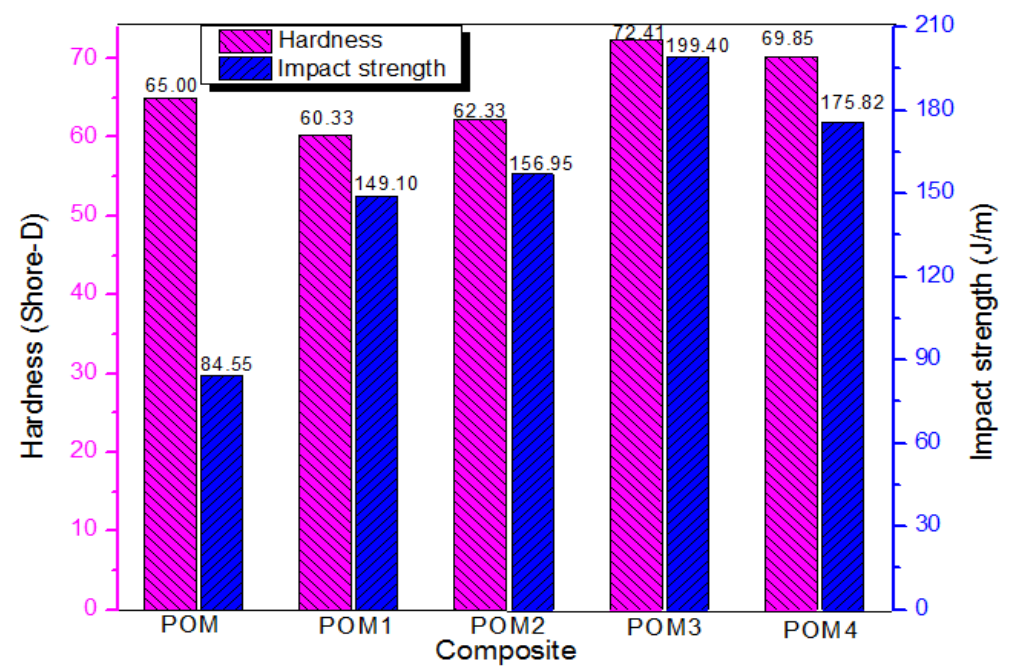

Figure 1: Hardness and Impact Strength of POM and Its Composite.

\section{Tensile Properties}

Variations in tensile strength of POM/SR blend based composites with and without aramid fiber along with different fillers are presented in the Table 4 . The tensile strength of AF/PTFE/SC/POM hybrid composites was $28.6 \%$ greater than that of the POM alone, compared to only a $23.8 \%$ increase in tensile strength for $\mathrm{MoS}_{2} / \mathrm{AF} / \mathrm{PTFE} / \mathrm{SC} / \mathrm{POM}$ hybrid composites over the pristine POM. Patrycjabazan et al. [31] reported that the POM with AF showed higher value of tensile strength than other composites. However, the composites which are not reinforced by aramid fiber POM1 and POM2 reduced the tensile strength by $24 \%$ and $29 \%$ respectively against neat POM. Similar trend may be observed except for the tensile modulus of the POM4 composites. 
The reduction in tensile strength in unfilled fiber composites may be attributed to two reasons: one reason may be due to the presence of pores at the interface between matrix and particulate fillers, the interfacial adhesion may be very poor to transfer the tensile stress. The other reason may be stress concentration in the polymer due to sharp corner points of irregular shaped particulate fillers.

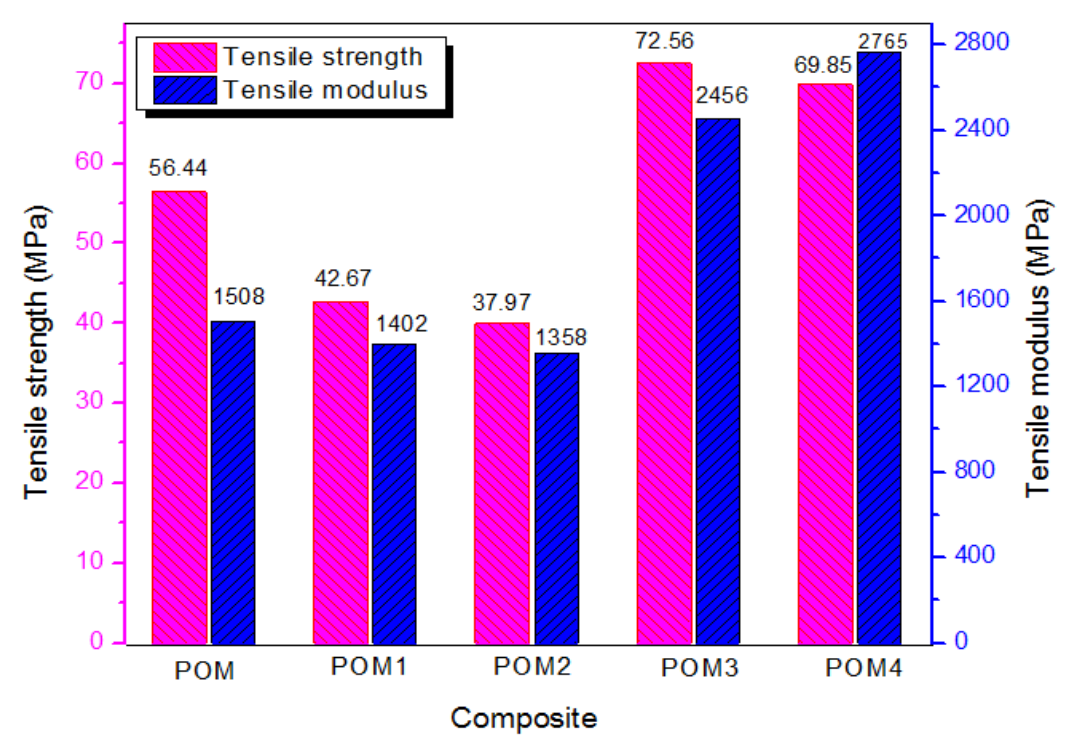

Figure 2: Tensile Strength and Modulus of POM Its Composites.

Tensile modulus of POM/SR blend based composites with and without short aramid fiber filled with various particulate fillers is shown in Figure2. The tensile modulus of POM3 and POM4 was significantly improved, while unfilled AF composites i.e. POM1 and POM2deteriorate its values than neat POM. Concerning mechanical properties, AF and PTFE additives show reverse effects [32]. The aramid fiber reinforced POM by increasing its modulus, and tensile strength, while PTFE micro-powder clearly damages these properties to certain extent. This behavior may be predictable as a result of stronger mechanical properties of aramid fibers with respect to POM matrix, compared to weaker mechanical properties of PTFE than POM.From the aforementioned discussion, in the present investigation, it has been observed that the tensile strength and modulus of the composites with AF fiber showed superior tensile strength and modulus than that of composites without aramid fibers.

\section{Flexural Properties}

It is necessary to develop the new components with enhanced flexural characteristics to prevent from failure due to bending, since they have to be used in structures. In the current work, the variation of flexural strength and modulus of various POM based composites are summarized in Table 4 and also shown in Figure 3. The flexural strength of AF filled hybrid composite (POM3) was 25\% higher than that of the POM alone, compared to only a $19 \%$ increase in tensile strength for POM4 hybrid composites over the pristine POM. While in unfilled AF composites (i.e. POM1 and POM2) there were no improvements of flexural properties, but deteriorate their values by $43 \%$ and $51 \%$ against POM alone. Similar trend can also be seen in flexural modulus. The reduction in the flexural strengths and modulus of the composites with filler and fiber content maybe due to an incompatibility of the particulates and the matrix material leading to poor interfacial bonding. The lower values of flexural properties may also be attributed to fiber to fiber contact, dispersion and voids problems. 
It is obvious from this study that as far as the flexural strength of composites concerned, aramid fiber reinforced composites found better than the composites without AFs.

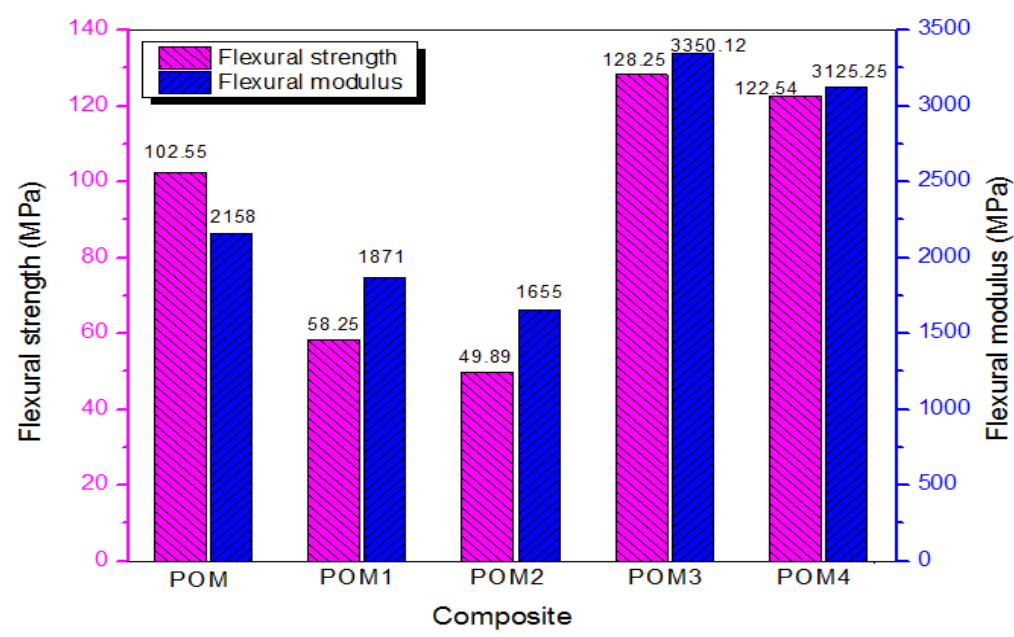

Figure 3: Flexural Strength and Modulus of POM Its Composites.

\section{Impact Strength}

Impact strength of material is its ability to absorb and dissipate energies under application of sudden or shocking load. Impact strength of POM/SR blend and its composites with and without AFs are listed in Table 4 and represented in Figure 4. AF reinforced POM/SR blend composite has highest value of impact strength among all the composites. The impact strength value of POM/SR blend as noted in the table is $159.1 \mathrm{~J} / \mathrm{m}$ which is much higher against $84.55 \mathrm{~J} / \mathrm{m}$ of neat POM, and with incorporation of PTFE, its strength further increased. As already noted above, the impact strength of composite reinforced by AF with 15 wt. \% (POM3) reached highest strength by $135.8 \%$ and reduced to $107.9 \%$ with incorporation of small quantity of $\mathrm{MoS}_{2}$ as against POM alone. The tensile and impact strength, of the PP/AF composites were significantly improved by the introduction of AFs with suitable loading of $20 \mathrm{wt}$. \% [33].Ramanjaneyalu et al. [34] reported that up to $6 \%$ of $\mathrm{MoS}_{2}$ in POM enhanced maximum impact strength by $23 \%$ than POM alone. Two important factors govern the enhancement in the impact strength of the composites. The first factor is the capability of the filler to absorb energy to avoid crack propagation; second one isthe good interfacial bonding between the fillers, fiber and matrix in the composite.

\section{Microstructure and Morphology of POM and their Composites}

Figures 4(a) - (e) show SEM micrographs of neat POM, packed with SR, PTFE, MoS 2 reinforced by Aramid Fibers. Morphology of neat POM was investigated by SEM and acquired micrograph reveals presence of rough surface with some micro voids as shown in Figure 4 (a) and (b) represents micrographs of SR crammed POM sample. Many dark regions may be observed along the surface of sample, they are actually bunches of SR fibrils. Here the dispersion and distribution of SR part are not sufficient. During injection moulding, it is noticed that the coalescence force causes the formation of long fibrils. Because, they have high aspect ratios, they may break at the time of injection moulding under high shear rate and can also bond together. Finally, bundle of fibrils may be formed. Micrograph of POM/SR/PTFE composite as shown in Figure 4(c) indicates non-uniform distribution of micro-fibrils and some fibril bundles are besides the analysed sample. It is understood that non-functionalized SR will not have a widespread effect, whether or not it is brought during the extrusion or injection moulding, due to the fact it will exclusively act as third segment because of non-existent useful group. 


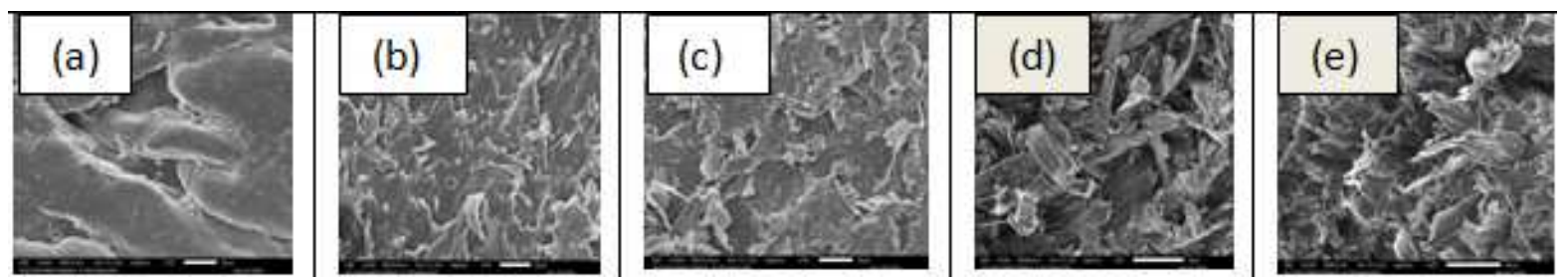

Figure 4: Microstructure of: a) neat POM (C) , b)POM/SR (C1), c) POM/SR/PTFE (C4), d) POM/SR/PTFE/AF (A1),e) POM/SR/PTFE/AF/MoS 2 (A2).

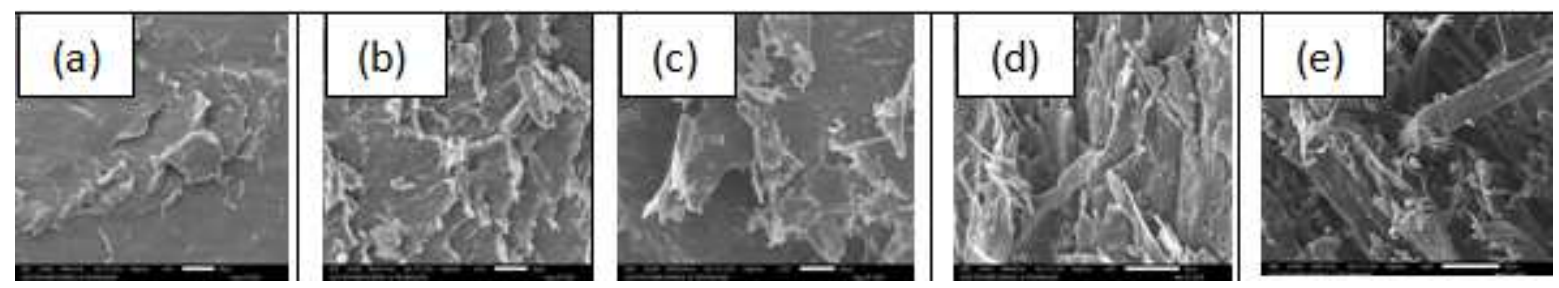

Figure 5: Micrographs of the Tensile Fractured Surface of: a) neat POM (C), b) POM/SR (C1), c) POM/SR/PTFE (C4),d) POM/SR/PTFE/AF (A1), e) POM/SR/PTFE/AF/MoS $($ A4).

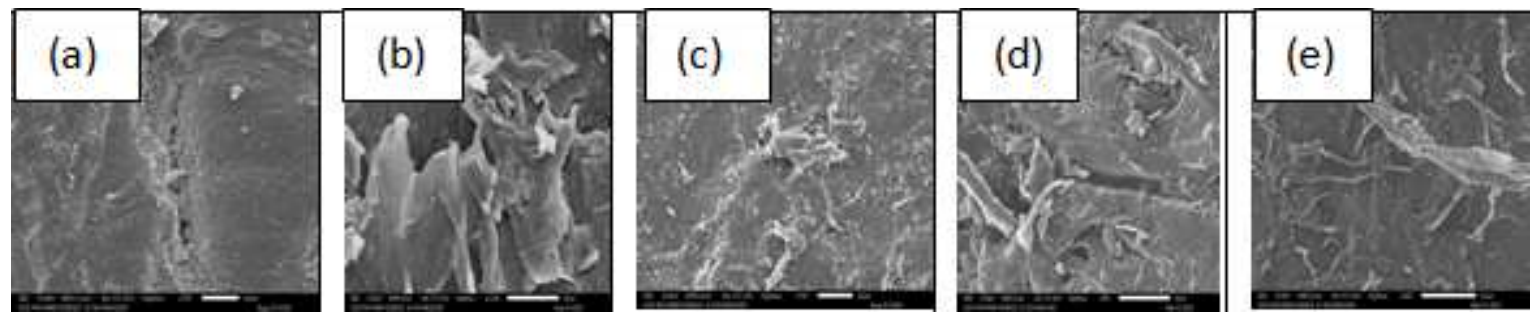

Figure 6: Micrographs of the Flexural Fractured Surface of :a) neat POM (C), b)POM/SR (C1), c)

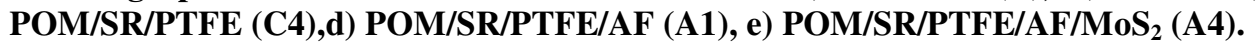

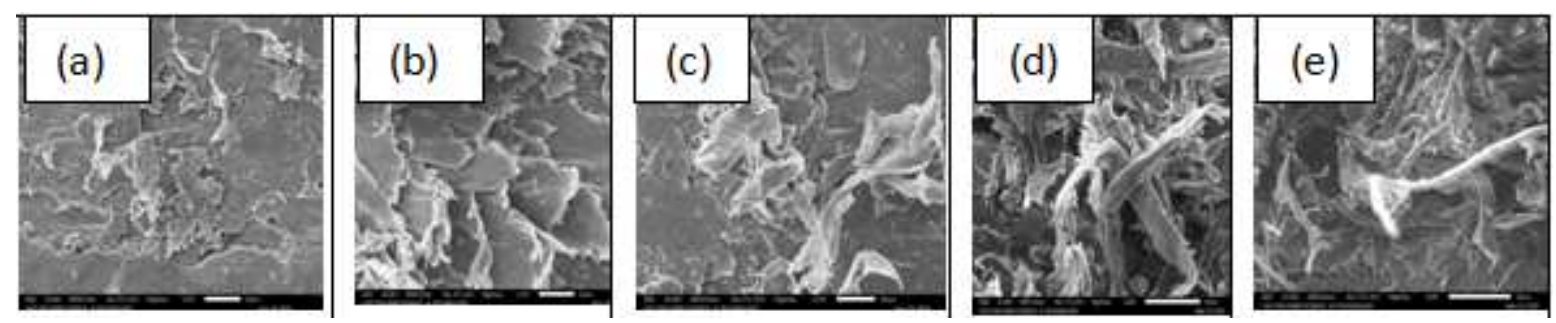

Figure 7: Micrographs of the Impact Fractured Surface of: a) neat POM (C), b)POM/SR (C1), c) POM/SR/PTFE (C4), d) POM/SR/PTFE/AF (A1), e) POM/SR/PTFE/AF/MoS 2 (A4).

Figure 5(a) - (e) show SEM micrographs of tensile fractured surface of POM/ /SR/AF/PTFE composites. Homogeneous distribution of SR\& PTFE particles in the POM matrix can be seen in 5b \&c and same occurrence was also explained in the literature [31].Figures 5, 6, and 7, represent the fractured surfaces of $\mathrm{AF}$ reinforced and $\mathrm{MoS}_{2}$ filled POM/SR composites and it can be observed that $\mathrm{AF} / \mathrm{MoS}_{2}$ exhibited higher solubility and good compatibility than PTFE/SR-POM composites. Both pull-out and breakage of fibers contribute dissipation of energy to the tensile fracture of the composites. Pull-out of PTFE\& $\mathrm{MoS}_{2}$ particles and deboning of fiber/filler-matrix are evident from the micrograph (Figure5e). For AF reinforced POM/SR (A1) composite, the mode of fracture of the composite is dominated by the deformation and fracture of the POM. 


\section{CONCLUSIONS}

- In the present investigation, it was observed that the composite with higher filler loading POM4 (A4) has more density and POM1 (C1) has least. Also noticed that composite with more filler loading more will be the void fraction.

- Hardness values of the AF reinforced composites found good compared to composites without AF and pristine POM. Impact strength of the composites reinforced by AF showed superior to other composites and virgin POM.

- Tensile and flexural properties of AF reinforced composites were improved significantly than composites without AF. Except tensile modulus, tensile strength and flexural properties of the composites filled with 2 wt. $\%$ of $\mathrm{MoS}_{2}$ reduces their value by $<7 \%$ but the tensile modulus was increased by $>12 \%$ than POM3 composite.

- SEM investigations of the fractured surfaces support the involved mechanisms during the mechanical testing process.

\section{REFERENCES}

1. Apichartpattanasiri, S., Hay, J. N. and Kukureka, S. N. (2001). A Study of the Tribological Behaviour of Polyamide 66 with Varying Injection Moulding Parameters. Wear, 251, 1557-1566.

2. Bahadur, S. and Gong, D. (1992). The Role of Copper Compounds as Fillers in Transfer Film Formation and Wear of Nylon. Wear, 154, 207-213.

3. Braydson, J. A. (1995). Plastic Materials. Wear, 141,159-83, Butterworth- Heinemann, Oxford, Lancaster.

4. Chang, L., Zhang, Z., Zhang, H. and Schlarb, A. K. (2005). On the Sliding Wear of Nanoparticle FilledPolyamide 66 Composites. Composites Science and Technology, 66(16), 3188-3198.

5. Rao, T. Indira, and Hongsandra Ramarao Nagendra. "The effect of active and silent music interventions on patients with type 2 diabetes measured with electron photonic imaging technique." Int J HumanitSocSci 3 (2014): 7-14.

6. Lu., Y, Chen., J. and Cui., $H$ Doping of carbon fiber into polybenzimidazole matrix and mechanical properties of structural carbon fiber-doped polybenzimidazole composites. Compos SciTechnol, 68, 3278-3284.

7. Long, C. and Hua, M. (2005). Study on POM composites modified by ekonol and lubricant. J Thermoplast Compos Mater, 18, $381-391$

8. Bijwe, J., Sen, S. and Ghosh, A., (2005). Influence of PTFE content in PEEK-PTFE blends on mechanical properties and tribo-performance in various wear modes. Wear, 258,1536-1542.

9. Agrawal, M. E. E. N. A., and A. R. V. I. N. D. Mittal. "Deployment of microgrids in the developed countries: an appraisal." International Journal of Electrical and Electronics Engineering Research (IJEEER) 4.3 (2014): 23-34.

10. Yang, S., Chen, Y., Yang, C. and Ding, W., (2017). The morphology evolution and crystallization behavior of microinjection molded polyoxymethylene/molybdenum disulfide nanocomposite. J ApplPolymSci 134, 1-13.

11. Unal, H. and Mimaroglu, A., (2003). Friction and wear behaviour of unfilled engineering thermoplastics. Mater Des, 24,183187.

12. Galeski, A., (2003). Strength and toughness of crystalline polymer systems. ProgPolymSci 28,1643-1699. 
13. Ota, W.N., Amico, S.C. and Satyanarayana, K.G., (2005). Studies on the combined effect of injection temperature and fiber content on the properties of polypropylene-glass fiber composites. Compos SciTechnol 65, 873-881.

14. RKJ, De Silva, and ThashikaRupasinghe. "Characterization of New Product Development (NPD) Models Applicable to Enhance the Overall Performance of the Apparel Industry." International Journal of Textile and Fashion Technology (IJTFT) $\operatorname{ISSN}(P)$ (2016): 2250-2378.

15. Hu, K.H., Wang, J., Schraube, S., Xu, Y.F., Hu, X.G. and Stengler, R., (2009). Tribological properties of MoS2 nano-balls as filler in polyoxymethylene-based composite layer of three-layer self-lubrication bearing materials. Wear 266, 1198-1207.

16. Q. Wang, Q. (2011). Thermal stability of polyoxymethylene and its blends with poly(ethylenemethylacrylate) or poly- (styrenebutadiene-styrene), J. Appl Poly Sci, 121, 376-388.

17. Mishra, R. M. and Rai, J.S.P. (2016). Polyetherimide /silicone rubber composite reinforced with nanosilica particles. Int. J. Scient. Technol Res, 5, 176-180.

18. Equbal, A., and R. A. J. K. U. M. A. R. Ohdar. "A Comprehensive Supply Chain Performance Measurement and Evaluation (CSPME) Methodology." International Journal of Mechanical and Production Engineering Research and Development (2017): 1-18.

19. Bhattacharya, M., Maiti, M., Bhowmick, A.K. (2009). Tailoring properties of styrene butadiene rubber nanocomposite by various nanofillers and their dispersion. Polym Eng. Sci, 49, 81-98.

20. Kulia, T., Srivastava, S.K., Bhowmick, A.K. (2009). Rubber/LDH nanocomposite by solution blending. J. Appl.PolymSci, 111, 635-641.

21. Bahadur S, Schwartz CJ (2008) Tribology of polymeric nanocomposites, chap. 2. In: Friedrich K, Schlarb AK (eds), Elsevier, Amsterdam, 2-7

22. Bahadur S, Gong D (1992) The action of fillers in the modification of the tribologicalbehavior of polymers. Wear 158:41-59

23. Wang $Q H$, Xue QJ, Liu WM, Chen JM (2000) The friction and wear characteristics of nanometer SiC and Polytetrafluoroethylene filled polyetheretherketone. Wear 243:140-146

24. Ни KH, Wang J, Schraube S, Хи YF, Hu XG, Stengler $R$ (2009) Tribological properties of MoS2 nano-balls as filler in polyoxymethylene- based composite layer of three-layer self-lubrication bearing materials. Wear 266:1198-1207

25. Simona Matei,Maria Stoicanescu,AurelCrisan. ( 2016). Composites with short fibres reinforcedepoxy resin matrix. Procedia Techonology9, 22, 174-181.

26. Herbert Yeung K K and Rao K P, (2012), Mechanical Properties of Kevlar-49 Fibre Reinforced Thermoplastic Composites. Polymer and Polymer Composites.Vol.20, Issue 5,411-424.

27. Prashanth, S., Subbaya, KM., Nithin, K. and Sachhidananda, S. (2017). Fiber Reinforced Composites - A Review. Material Science Engineering, 6:3.

28. Sarikanat, M. (2008). Experimental characterization and morphology investigation of composites based on high-density and low-density polyethylene reinforced with non-crimp-stitched glass fabrics. Polymer Composites, 28, 938-948.

29. Cuong, N.K. (1997). Analytical methods for prediction of tensile properties of plain knitted fabric reinforced composites. Advanced Composite Materials, 6, 123-151. 
30. Karger-Kocsis, J. (2005). Textile fabric-reinforced thermoplastic polyester composites. Handbook of Thermoplastic Polymers, Homopolymers, Copolymers, Blends, and Composites, Handbook of Thermoplastic Polymers. Homopolymers, Copolymers, Blends, and Composites. 24, 1133 - 1171.

31. Fakhar, A., Razzaghi-Kashani, M. and Mehranpour, M., (2013). Improvements in tribological properties of polyoxymethylene by aramid short fiber and polytetrafluoroethylene. Iran Polym J 22, 53-59.

32. Samyn $P$ and Schoukens G. Tribological properties of PTFE $\square$ filled thermoplastic polyimide at high load, velocity, and temperature. Polym Compos 30, 1631(2009).

33. JayashreeBijwe, Sukanta Sen, and Anup Ghosh. (2005). Influence of PTFE content in PEEK-PTFE blends on mechanical properties and tribo-performance in various wear modes. Wear, 258, 1536-1542.

34. R. Hemanth, M. Sekar, and B. Suresha (2014), Effects of Fibers and Fillers on Mechanical Properties of Thermoplastic Composites, Indian Journal of Advances in Chemical Science, 2, 28-35.

35. PatrycjaBazan, StanisławKuciel and Marek Nykiel (2018), Characterization of Composites Based on Polyoxymethylene and Effect of Silicone Addition on echanical and TribologicalBehavior, Polymer Engineering and Science, 1-6.

36. AfsanehFakhar, Mehdi Razzaghi-Kashani, MiladMehranpour, (2013) mprovements in tribological properties of Polyoxymethylene by aramid short fiber and Polytetrafluoroethylene, Iran Polym J, 22, 53-59.

37. Xiaosui Chen, Sheng Zhang, Guozhi Xu, Xinjun Zhu, and Wei Liu (2012) Mechanical, Flammability, and Crystallization Behavior of Polypropylene Composites Reinforced by Aramid Fibers. Journal of Applied Polymer Science, 125, 1166-1175.

38. Ramanjaneyulu G and Rajendran R, (2017), Study of Wear Behaviour of POM/Graphite and POM/MoS2 Composites. SAE Technical Paper 2017-28-1988,

39. R. Jeziórska., R, Swierz-Motysia., B, Szadkowska., A, Marciniec., BH. Maciejewski., H, Dutkiewicz. M, and Leszczy'nska, I.(2011).Effect of POSS on morphology, thermal and mechanical properties of polyamide 6. Polimery, 56, 809-816. 

